\title{
Virtual Postcards from the Feminist Utopia http:www.escape.ca/ mawa
}

Curated by Lori Weidenhemmer for Mentoring Artists for Women's Art Marina Zurkow

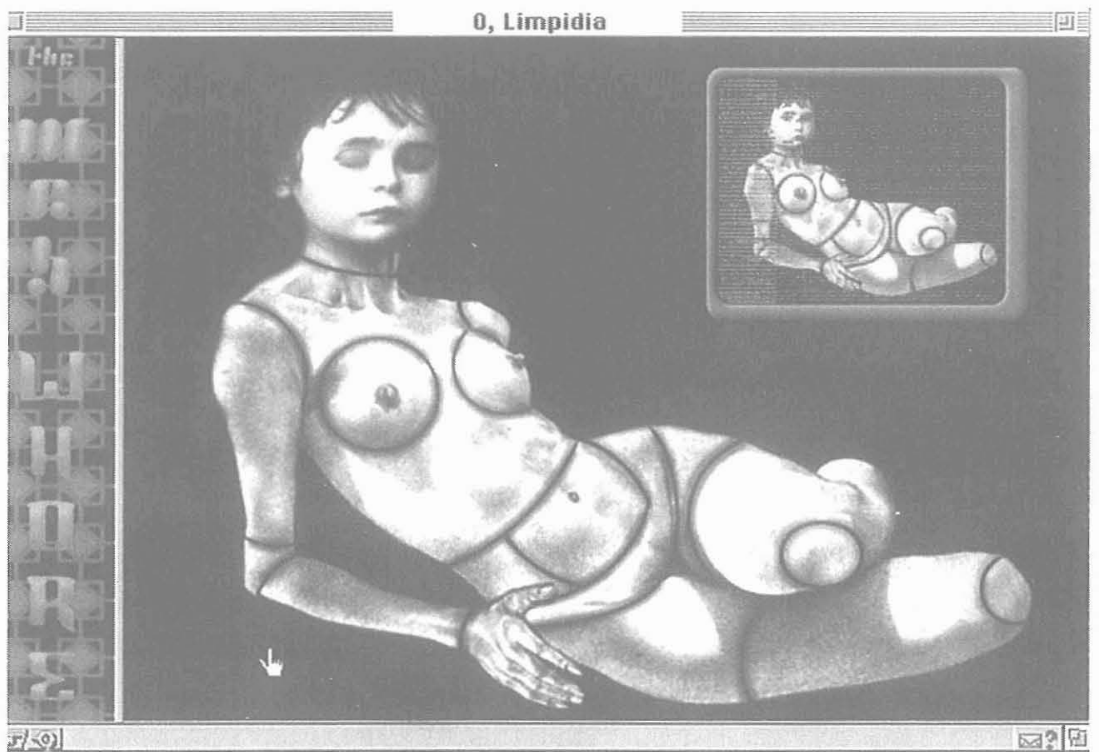


Lori Blondeau
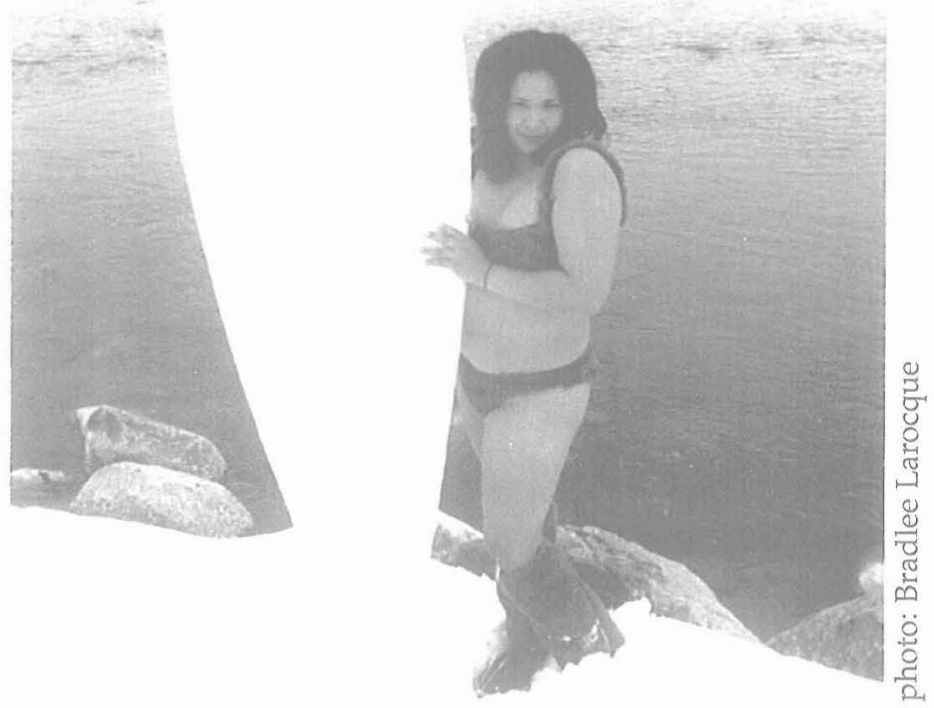

lonely surfer squaw 


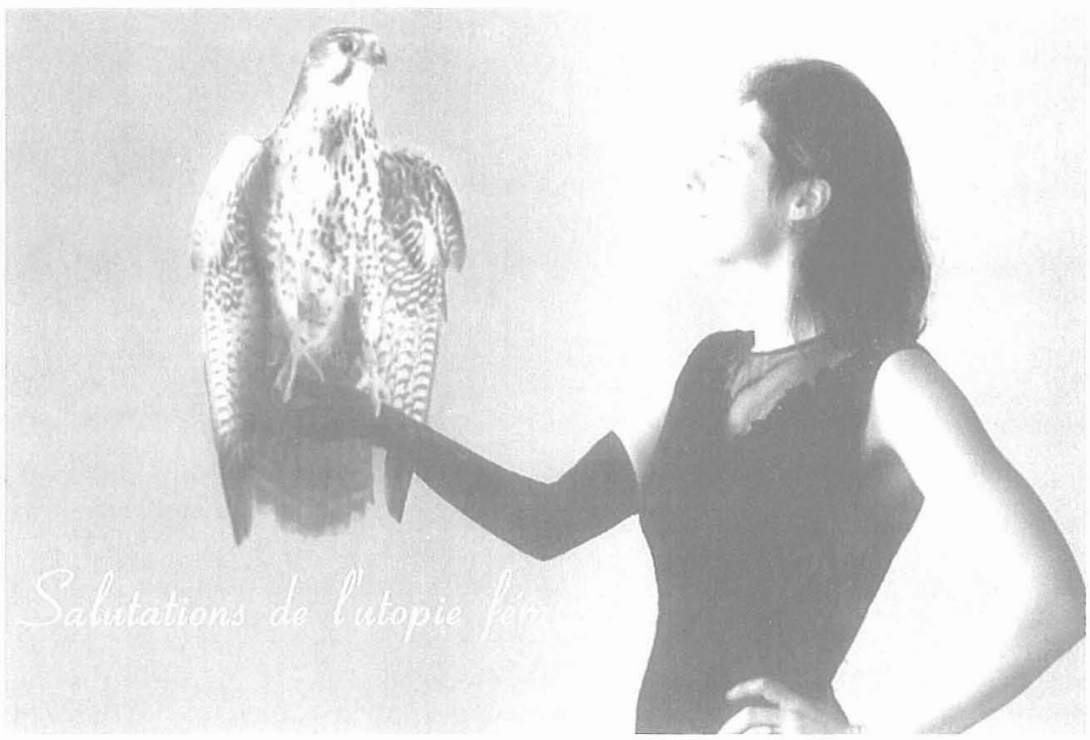

Sue Bustin:

In the feminist utopia we know that the world's sout is held in the hearts of birds and animals

\section{Postcard}

\section{Dear Mildred,}

Salut! Here in Fem.Ut. everyone speaks French. It seems the langunge of love, of poetry, of fine cuisine has replaced that of incernational commerce and wum. I thinh it also has something to do with honoring the great French fem. inist uriters of the early $20 \mathrm{sh}$ C. The food here is fanterstic and the air filled with the sounds of happy Rids and bird song. You must come here on your vacation mest year!

rosor sue

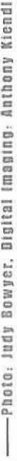

Virtual Postgards from the Feminist Utonia

hนtp://www.escape.ca/ mawa

Produged with supuort from the Hanitoba Arts Goungil and hentoring Artigts for Women's art 